OPEN ACCESS

Edited by:

Jeremy Kiszka,

Florida International University,

United States

Reviewed by:

Mourier Johann,

USR 3278 Centre de Recherche

Insulaire et Observatoire

de l'Environnement (CRIOBE), France

Yannis Peter Papastamatiou,

Florida International University,

United States

*Correspondence:

R. J. David Wells

wellsr@tamug.edu

Specialty section:

This article was submitted to

Marine Megafauna,

a section of the journal

Frontiers in Marine Science

Received: 20 July 2018

Accepted: 22 August 2018

Published: 10 September 2018

Citation:

Wells RJD, TinHan TC, Dance MA

Drymon JM, Falterman B,

Ajemian MJ, Stunz GW, Mohan JA, Hoffmayer ER, Driggers WB III and

McKinney JA (2018) Movement,

Behavior, and Habitat Use of a Marine

Apex Predator, the Scalloped

Hammerhead. Front. Mar. Sci. 5:321.

doi: 10.3389/fmars.2018.00321

\section{Movement, Behavior, and Habitat Use of a Marine Apex Predator, the Scalloped Hammerhead}

\author{
R. J. David Wells ${ }^{1,2 *}$, Thomas C. TinHan ${ }^{1}$, Michael A. Dance ${ }^{1,3}$, J. Marcus Drymon ${ }^{4}$, \\ Brett Falterman ${ }^{5}$, Matthew J. Ajemian ${ }^{6}$, Gregory W. Stunz ${ }^{7}$, John A. Mohan ${ }^{1}$, \\ Eric R. Hoffmayer ${ }^{8}$, William B. Driggers III ${ }^{8}$ and Jennifer A. McKinney ${ }^{5}$
}

\begin{abstract}
${ }^{1}$ Department of Marine Biology, Texas A\&M University at Galveston, Galveston, TX, United States, ${ }^{2}$ Department of Wildlife and Fisheries Sciences, Texas A\&M University, College Station, TX, United States, ${ }^{3}$ Department of Oceanography and Coastal Sciences, Louisiana State University, Baton Rouge, LA, United States, ${ }^{4}$ Coastal Research and Extension Center, Mississippi State University, Biloxi, MS, United States, ${ }^{5}$ Louisiana Department of Wildlife and Fisheries, Baton Rouge, LA, United States, ${ }^{6}$ Harbor Branch Oceanographic Institute, Florida Atlantic University, Ft. Pierce, FL, United States, ${ }^{7}$ Harte Research Institute for Gulf of Mexico Studies, Texas A\&M University - Corpus Christi, Corpus Christi, TX, United States, ${ }^{8}$ Southeast Fisheries Science Center, Mississippi Laboratories, National Marine Fisheries Service, Pascagoula, MS, United States
\end{abstract}

Conservation and management efforts of marine apex predators are more reliable when information on movement and habitat use patterns are known. The scalloped hammerhead (Sphyrna lewini) was the first shark species to be protected under the U.S. Endangered Species Act and has life history characteristics that make this species particularly at risk for local depletion. Consequently, the goal of this study was to better understand the movement dynamics of this species in the Gulf of Mexico (GOM) where discards through the longline fishery can be substantial. A total of 33 scalloped hammerheads were tagged with fin mounted satellite tags and tracked for an average of 146 days (ranging from 5 to 479 days) to examine horizontal movements and quantify space use. Scalloped hammerheads showed a wide range of movements throughout the GOM continental shelf with limited long-distance dispersal and females displayed a shelf-edge association relative to more mid-shelf use by males. A generalized additive model was developed to identify habitat suitability for scalloped hammerheads in the GOM, while state-space modeling was used to examine movement behaviors. Model results highlighted the use of continental shelf waters with high occurrence at close proximities to both artificial and hard-bottom habitat combined with low chlorophyll a concentrations ( $\sim-4 \mathrm{mg} \mathrm{m}^{-3}$ ) and moderate salinities (33-35.5). Habitat suitability for scalloped hammerheads was predicted to be high on the mid to outer continental shelf inside the $200 \mathrm{~m}$ isobath and state-space model results suggest area-restricted behavior was most common relative to transient behavior. Findings from this study provide important information on movement of this species in the GOM and highlight their restricted use of continental shelf habitat and resident behavior that will need to be incorporated in future stock assessments and extinction risk analyses. 


\section{INTRODUCTION}

Information on movement and habitat use of marine apex predators is needed to better understand population structure and to implement spatially explicit management strategies. Apex predators provide an important role in ecosystem stability since they are top consumers in the food web (Myers and Worm, 2003; Scheffer et al., 2005). Consequently, proper management of marine predators requires a fundamental understanding of the environmental processes driving their movements and behavior (Schlaff et al., 2014). Identifying important habitat and the factors responsible for movement are inherently difficult due to the mobility of large marine predators as they often traverse multiple jurisdictional boundaries, ecosystems, and habitats (Chin et al., 2017). Moreover, patterns of habitat use and residency are influenced by dynamic oceanographic conditions (e.g., shifting eddies or currents) and distribution and movement of prey resources (Brill et al., 1999; Queiroz et al., 2016). Physicochemical properties are increasingly used to delineate habitat boundaries and predict migratory trajectories (Block et al., 2001; Teo et al., 2007; Sequeira et al., 2012), and habitat utilization patterns have been described for several marine species, including large sharks (Block et al., 2011; Hammerschlag et al., 2011). Tagging methods (e.g., acoustic telemetry and archival tagging) have been used to discern habitat use and associated data provide fisheries managers with a more complete picture of the environmental and oceanographic conditions that influence movement and can be used in ecosystem-based fisheries management. Unfortunately, due to cost and logistical constraints, basic data on habitat use and movement are limited for many shark species, including many important stocks in the North Atlantic Ocean and associated basins, such as the Gulf of Mexico (GOM).

The scalloped hammerhead (Sphyrna lewini) is a circumglobal shark species that lives in warm temperate and tropical seas (Compagno, 1984). This species is highly mobile, capable of extensive migrations, and is generally found across a mosaic of ecosystems including bays and estuaries, continental shelves, and offshore pelagic waters (Compagno, 1984; Spaet et al., 2017). Current concerns over the population status of scalloped hammerheads include temporal declines in abundance (Baum and Blanchard, 2010; Powers et al., 2013) and high atvessel mortality rates (Morgan and Burgess, 2007). Scalloped hammerheads are primarily caught in targeted commercial shark fisheries, as well as bycatch in longline and coastal gillnet fisheries with mortality estimates sometimes exceeding $90 \%$ of individuals landed (Morgan and Burgess, 2007). Scalloped hammerheads are also captured in land-based shark fisheries in the GOM (Ajemian et al., 2016), and exhibit increased physiological sensitivity to capture stress compared to other pelagic sharks (Gallagher et al., 2014). This species has a high risk of overexploitation due to a late age of maturity and relatively slow growth (Cortes, 2000; Piercy et al., 2007). In addition, schooling behavior by this species makes them particularly vulnerable to capture in relatively large numbers (Hayes et al., 2009). Scalloped hammerhead fins are highly valued in the shark fin trade (Abercrombie et al., 2005) with estimates ranging between 1.3 and 2.7 million scalloped and smooth hammerheads (S. zygaena) used in the Hong Kong fin trade annually (Clark et al., 2006; Camhi et al., 2009). Following a petition to list scalloped hammerheads on the Endangered Species List in 2011, an extinction risk analysis (ERA) team provided a status review and assessed the risk of extinction (Miller et al., 2014), resulting in this species becoming the first shark to be protected under the U.S. Endangered Species Act for populations in the eastern Atlantic and Pacific Ocean. The risk of extinction for scalloped hammerheads in the GOM and northwest (NW) Atlantic Ocean was classified as low to moderate, but this population has suffered an $83 \%$ decline since 1981 due to commercial and recreational fishing (Hayes et al., 2009). As a result, the ERA suggested that the low levels of abundance combined with susceptible life history characteristics make this species particularly at risk for local depletion.

Population structure and connectivity studies on scalloped hammerheads have found variable patterns. Evidence suggests substantial genetic heterogeneity for a large marine predator on a global scale (Duncan et al., 2006) and multiple subpopulations and cryptic speciation in the western North Atlantic Ocean (Quattro et al., 2006; Chapman et al., 2009). Tagging studies demonstrate that scalloped hammerheads have the capacity to travel distances exceeding $1,000 \mathrm{~km}$ (Kohler and Turner, 2001; Bessudo et al., 2011; Spaet et al., 2017). However, several studies have found that scalloped hammerheads have relatively small home ranges and display aggregative behaviors around bathymetric features, such as seamounts, potentially due to enhanced prey availability, geomagnetic associations from gradients in the seafloor, or simply short durations of tagged individuals (Klimley, 1993; Hearn et al., 2010). Other studies have observed ontogenetic differences in habitat use; for example, Duncan and Holland (2006) found juvenile scalloped hammerheads remained within a bay system for up to their first year of life before moving to offshore coastal areas. Consequently, a better understanding of shark movement patterns in relation to environmental conditions within the GOM is critical for proper conservation and successful management of this species.

The GOM is a highly productive marginal sea with unique oceanographic conditions influencing the distribution and abundance of sharks as well as other large marine predators (Richards et al., 1989; McKinney et al., 2012). Significant nutrient loading from the Mississippi River coupled with oceanic conditions (due to the proximity of slope waters to shore) results in optimal environments for many forage species and consequently large predators (Chesney et al., 2000). In addition, the basin is dominated by a unique physical feature, the loop current (LC), which influences the productivity and physicochemical parameters within the region (Biggs, 1992). The LC consists of warm surface waters from the Caribbean Sea entering the GOM through the Yucatan Strait, and flows clockwise around a surface "dome" of water before exiting through the Straits of Florida (Oey et al., 2005). Portions of the LC often spin off, forming cold and warm core eddies that drift into the NW GOM (Oey et al., 2005). As a result, this physical feature, combined with the Mississippi River plume, essentially divides the GOM into two unique oceanographic regions that influence habitat use patterns of pelagic fishes (Richards et al., 1989; Kraus and Rooker, 2007; Teo et al., 2007). Undoubtedly, differences in 
habitat use between the two regions is critical data that needs to be incorporated into habitat standardization procedures and it is therefore important to investigate the east-west barrier that the LC may present to mixing within the GOM, which may lead to differences in stock structure of sharks such as the scalloped hammerhead.

The objectives of this study were to characterize movement dynamics of scalloped hammerheads throughout the GOM. We were specifically interested in quantifying horizontal movements (i.e., space use), characterizing habitat associations in relation to environmental parameters, and developing predictive models to identify habitat suitability for scalloped hammerheads in the GOM based on their movement behaviors (i.e., area restricted, transiting).

\section{MATERIALS AND METHODS}

\section{Study Area and Tagging}

Tagging activities occurred throughout the northern GOM including the northeast (NE) off Alabama and Florida, northcentral (NC) off Louisiana, NW (NW) off Texas, United States. Tagging procedures occurred through hook and line fishing from sportfishing vessels or through fishery independent bottom longline (BLL) sampling. For hook and line fishing, once caught using either live or dead bait, the animal was immediately brought alongside the vessel and retained in the water for tagging procedures while some individuals were brought onboard with a cradle during the longline sampling. Scalloped hammerheads captured and tagged during fishery-independent BLL sampling followed methods outlined in Drymon et al. (2010). Briefly, a BLL consisting of $1.85 \mathrm{~km}$ of $4-\mathrm{mm}$ monofilament (545-kg test) mainline was set with 100 gangions. Gangions were $3.66 \mathrm{~m}$ (3$\mathrm{mm}$ monofilament) in length and consisted of a longline snap and a 15/0 circle hook (Mustad model 39960D) baited with Atlantic mackerel (Scomber scombrus). All bottom longline BLLs were set for $1 \mathrm{~h}$.

During tagging, two to four small holes were drilled into the distal portion of the leading edge of the dorsal fin for placement of a smart position or temperature (SPOT) transmitter tag (Wildlife Computers, Seattle, WA, United States). Tags were coated in black anti-fouling paint (Micron 66, Interlux ${ }^{\circledR}, \mathrm{NJ}$, United States) to prevent growth of fouling organisms, and sharks tagged in Texas were equipped with copper sensors and an extrastiff antenna. Transmitters were programmed with a maximum allotment up to 250 transmissions per day. Shark tracks were filtered to remove poor location class (Z) positions. For days in which multiple positions were recorded for an individual shark, the highest quality location class position for each day was retained. The SPOT tag was positioned on the dorsal fin to facilitate near real-time tracking via Argos satellites during surface interval periods. Prior to release, the fork length (FL, cm) was measured and sex of each shark were recorded.

\section{Space Use}

Activity space use and site fidelity estimates were calculated in the rhr package (Signer and Balkenhol, 2015) in R (R Development
Core Team, 2011). Kernel density estimation (KDE) was used to quantify the activity space of individual sharks $(n=26$; sharks with fewer than 20 total detections were excluded due to limited data) using reference bandwidth estimation. We defined areas of core use as those constrained by $50 \% \mathrm{KDE}$ isopleths (TinHan et al., 2018). Two movement metrics [mean squared distance (MSD) from center of activity and linearity index (LI)] were calculated for individual animal tracks and for 100 random trajectories. MSD from center of activity was calculated as a metric of dispersion of positions around the centroid of the track. LI was calculated as the linear distance between the first and last position of an individual track divided by the sum of distances between each position (total distance traveled), where values approaching 1 indicate linear paths and values approaching 0 indicate tortuous paths. Animal tracks significantly more constrained (MSD) or less linear (LI) $(p<0.05)$ than the distributions of MSD and LI values from randomly generated trajectories were considered indicative of site fidelity (Spencer et al., 1990). The relationship between core area size and shark size (FL), and core area size and sex were tested with a linear regression and Kruskal-Wallis one-way ANOVA, respectively.

\section{Environmental Data}

A suite of environmental variables were used to relate to scalloped hammerhead occurrence including chlorophyll $a$ concentration (chl $a$ ), salinity, sea surface height anomaly (SSHA), sea surface temperature (SST), bathymetric slope, depth, distance to artificial structure, and distance to hard-bottom habitat. Oceanographic data (chl $a$, salinity, SSHA, SST) were extracted over the duration of the study period (19 September 2012 to 19 July 2016) using the Marine Geospatial Ecology Toolbox (v. 0.8a68, Roberts et al., 2010) in ArcMap 10.4.1 (ESRI). Mean 8-day and monthly chl $a$ data were obtained from the Moderate Resolution Imagine Spectroradiometer (MODIS) at a $4 \mathrm{~km}$ resolution. For grid cells obscured by cloud cover in the 8-day data, monthly mean values of chl $a$ were used. Daily mean SST ( $4 \mathrm{~km}$ resolution) and salinity (7.8 km resolution) were obtained from the Hybrid Coordinate Ocean Model (HYCOM) data server. SSHA (24 km resolution) data were obtained from the Aviso altimetry dataset, and the Copernicus Marine Environment Monitoring Service (CMEMS).

Bathymetry data $(0.003 \mathrm{~km}$ resolution) for the GOM were downloaded from the Scripps Institution of Oceanography ${ }^{1}$ (Becker et al., 2009). Kriging interpolation methods were used to create a continuous raster surface to estimate benthic sediment composition (\% rock, gravel, sand, mud) using sediment data from the United States Geological Survey $\left(U_{S G S}{ }^{2}\right.$ ) usSeabed data set (Buczkowski et al., 2006). Hard-bottom habitat was then classified as areas comprised of greater than $25 \%$ rock substrate. Locations of standing oil and gas platforms were obtained from the Bureau of Ocean Energy Management (BOEM), while the locations of known artificial reefs were obtained from data sets compiled by both BOEM and National Oceanic and Atmospheric Administration (NOAA) (Supplementary Figure S1). For the purpose of our models, these two data sets (oil and gas platforms

\footnotetext{
${ }^{1}$ http://topex.ucsd.edu/WWW_html/srtm30_plus.html

${ }^{2}$ https://pubs.usgs.gov/ds/2006/146/htmldocs/usseabed.htm
} 
as well as artificial reefs) were combined and collectively referred to as artificial habitat. Distance to the nearest artificial and hardbottom habitat was calculated as the shortest in-water distance from a sampling location using the Cost Distance tool in ArcGIS.

\section{Habitat Modeling}

A generalized additive modeling (GAM) framework similar to Aarts et al. (2008) was used to examine species-habitat relationships and to predict the distribution of suitable habitat in the northern GOM. Daily positions of sharks represented a sample of telemetry positions visited by each shark (presence). Each presence was complemented by a sample position representing a location that the shark did not visit (absence) randomly drawn from a surface of accessibility based on the elapsed time between positions and the estimated maximum sustained swimming speed of scalloped hammerheads $(\sim 1$ body length $\mathrm{s}^{-1}$; Lowe, 1996; Ryan et al., 2015). This process ensured that each absence was in a location that could be realistically reached by scalloped hammerheads (based on the previous position). In addition, because each absence is matched temporally to a telemetry position, we can assume that the shark did not visit that position in space at that time (Aarts et al., 2008). A binomial GAM with individual included as a random factor was then used to evaluate the effects of the eight environmental variables ( $\mathrm{chl} a$, salinity, SSHA, SST, depth, bathymetric slope, distance to artificial structure, and distance to hard-bottom habitat) on the presence of scalloped hammerheads. Binomial GAMs were fit in the mgcv package (Wood, 2006) in $\mathrm{R}$, with a logit link function and cubic regression splines restricted to a maximum of four degrees of freedom in order to avoid overfitting (Ciannelli et al., 2008). A manual stepwise backward selection procedure based on minimizing Akaike's information criterion (AIC; Akaike, 1974) was used to select variables explaining the presence of scalloped hammerheads. Non-significant variables $(p$-value $<0.05)$ were removed from the final model if variable exclusion resulted in a $\triangle \mathrm{AIC}<2$ (Burnham and Anderson, 2002). Prior to backward selection, all variables were tested for collinearity using variance inflation factor (VIF), and variables with VIF $>2$ were removed from analysis. There was no collinearity detected among the variables selected. The relative importance of each predictor variable in the final model was assessed by examining the difference in AIC $(\triangle \mathrm{AIC})$ and percent deviance explained $(\Delta \mathrm{DE})$ when each variable was removed from the final model (Rooker et al., 2012).

The best-fit model was then used to assess the spatial distribution of suitable habitat for scalloped hammerheads within the northern GOM. Oceanographic and habitat data for model predictions were obtained in the same manner as previously described for telemetry data, with the exception that oceanographic data (chl $a$, salinity, SSHA, and SST) were based on cumulative means across summer months over a single year (01 July 2016 to 30 September 2016). Environmental data were extracted to prediction grids $\left(\right.$ resolution $=0.05^{\circ}$ ) and used to predict the probability of occurrence of scalloped hammerheads at each grid point using the predict.gam function in R. For visualization, grid points were kriged in ArcGIS to create a continuous raster surface and smoothed using bilinear interpolation. For the purposes of this study, habitat suitability was then classified based on probability of occurrence as: high $(>0.66)$, moderate $(0.33-0.66)$, and low $(<0.33)$.

\section{State-Space Modeling}

A first-difference correlated random walk switching (DCRWS) model was used to initially identify whether scalloped hammerheads exhibited multiple modes of movement behavior (area restricted, unclassified, transiting) over the course of a track. Bayesian DCRWS models permit estimation of states (i.e., biological parameters, including discrete behavioral modes) at regular intervals throughout potentially irregular time series data, and the probability of switching between behavioral modes at each interval, while making allowances for observational errors such as those inherent in satellite tag data. Models were run on individual sharks with at least 20 location estimates $(n=26)$ using JAGS 4.0.0 (Just Another Gibbs Sampler) via package bsam in R. Markov chain Monte Carlo (MCMC) techniques were used to produce mean estimates of location $\left(\Sigma_{\text {latitude, }}, \Sigma_{\text {longitude }}\right)$, and random walk index (turning angle and speed). Random walk index estimates were then used to estimate behavioral mode $\left(b_{t}\right)$ where values range from 1 to 2 . Values of $b_{t}$ approaching 1 indicate area-restricted movement, and values approaching 2 indicate transiting movement. Continuous estimates of $b_{t}$ were classified into discrete behavioral modes where values $<1.25$ were considered as area-restricted movements and values $>1.75$ were considered as transiting movements (Jonsen et al., 2007). Where switches among multiple behavioral modes could not be identified, a first difference correlated random walk (DCRW) model was fit to all shark tracks. To characterize the movements of tagged scalloped hammerheads, random walk index $\gamma$ was estimated in the DCRW model, where $0<\gamma<1$. Similar to behavioral mode classification, values of $\gamma$ approaching 0 indicate uncorrelated turning angle and speed at each location (simple random walk), while values approaching 1 indicate more linear tracks, with autocorrelation in turning angle and speed (correlated random walk). DCRWS and DCRW models regularized samples to $12 \mathrm{~h}$ time intervals for each animal, and were fit using 45,000 MCMC samples, with a burn in of 5,000, and thinned by a factor of 4 (final MCMC length: 10,000 samples). The Raftery-Lewis diagnostic (Raftery and Lewis, 1992) was used to estimate minimum MCMC lengths and thinning factors to precisely estimate posterior sample quantiles, and Gelman-Rubin's diagnostic (Gelman and Rubin, 1992) was used to confirm model convergence.

\section{RESULTS}

A total of 33 scalloped hammerheads were captured and tagged throughout the northern GOM and consisted of 11 in the NE, 17 in the NC, and five individuals in the NW GOM (Table 1). Eighty five percent $(n=28)$ of tagged sharks were males and $15 \%(n=5)$ 
TABLE 1 | Summary information from SPOT tag deployments on scalloped hammerheads in the Gulf of Mexico.

\begin{tabular}{|c|c|c|c|c|c|c|c|c|}
\hline Fish ID & $\begin{array}{l}\text { Length } \\
\text { (cm FL) }\end{array}$ & Sex & $\begin{array}{l}\text { Deployment } \\
\text { date }(M / D / Y)\end{array}$ & $\begin{array}{l}\text { Deployment } \\
\text { region }\end{array}$ & $\begin{array}{l}\text { Deployment } \\
\text { location }\end{array}$ & $\begin{array}{l}\text { Date of last } \\
\text { transmission }\end{array}$ & $\begin{array}{l}\text { Location of last } \\
\text { transmission }\end{array}$ & $\begin{array}{c}\text { Days at } \\
\text { liberty }\end{array}$ \\
\hline 1 & 173 & $\mathrm{~F}$ & $3 / 15 / 13$ & $\mathrm{NE}$ & $28.63 \mathrm{~N}, 89.57 \mathrm{~W}$ & $9 / 24 / 13$ & $29.24 \mathrm{~N}, 88.36 \mathrm{~W}$ & 193 \\
\hline 2 & 153 & $M$ & $5 / 5 / 14$ & $\mathrm{NE}$ & $29.97 \mathrm{~N}, 87.69 \mathrm{~W}$ & $7 / 30 / 14$ & $29.38 \mathrm{~N}, 88.65 \mathrm{~W}$ & 86 \\
\hline 3 & 148 & $M$ & $5 / 5 / 14$ & NE & $29.92 \mathrm{~N}, 87.58 \mathrm{~W}$ & $6 / 8 / 14$ & $29.55 \mathrm{~N}, 84.89 \mathrm{~W}$ & 34 \\
\hline 4 & 158 & $M$ & $5 / 5 / 14$ & NE & $29.87 \mathrm{~N}, 87.61 \mathrm{~W}$ & $9 / 30 / 14$ & $29.76 \mathrm{~N}, 88.33 \mathrm{~W}$ & 148 \\
\hline 5 & 143 & $M$ & $8 / 21 / 14$ & $\mathrm{NE}$ & $29.77 \mathrm{~N}, 88.36 \mathrm{~W}$ & $11 / 4 / 14$ & $29.76 \mathrm{~N}, 88.23 \mathrm{~W}$ & 75 \\
\hline 6 & 135 & $M$ & $8 / 22 / 14$ & NE & $29.47 \mathrm{~N}, 87.94 \mathrm{~W}$ & $9 / 19 / 14$ & $28.89 \mathrm{~N}, 90.35 \mathrm{~W}$ & 28 \\
\hline 7 & 102 & $\mathrm{~F}$ & $5 / 14 / 15$ & $\mathrm{NE}$ & $29.37 \mathrm{~N}, 88.09 \mathrm{~W}$ & $7 / 11 / 15$ & $28.19 \mathrm{~N}, 92.69 \mathrm{~W}$ & 58 \\
\hline 8 & 205 & $M$ & $5 / 14 / 15$ & NE & $29.38 \mathrm{~N}, 88.20 \mathrm{~W}$ & $8 / 16 / 16$ & $29.32 \mathrm{~N}, 88.22 \mathrm{~W}$ & 460 \\
\hline 9 & 114 & $M$ & $5 / 14 / 15$ & $\mathrm{NE}$ & $29.87 \mathrm{~N}, 88.29 \mathrm{~W}$ & $6 / 13 / 15$ & $30.00 \mathrm{~N}, 88.26 \mathrm{~W}$ & 30 \\
\hline 10 & 126 & $M$ & $5 / 14 / 15$ & $\mathrm{NE}$ & $29.87 \mathrm{~N}, 88.29 \mathrm{~W}$ & $7 / 20 / 15$ & $29.71 \mathrm{~N}, 88.78 \mathrm{~W}$ & 67 \\
\hline 11 & 122 & $M$ & $5 / 27 / 15$ & NE & $30.15 \mathrm{~N}, 88.21 \mathrm{~W}$ & $10 / 4 / 15$ & $29.85 \mathrm{~N}, 88.77 \mathrm{~W}$ & 130 \\
\hline 12 & 120 & $M$ & 8/19/12 & $\mathrm{NC}$ & $27.02 \mathrm{~N}, 83.98 \mathrm{~W}$ & $12 / 18 / 12$ & $27.26 \mathrm{~N}, 83.20 \mathrm{~W}$ & 121 \\
\hline 13 & 170 & $M$ & $9 / 18 / 12$ & $\mathrm{NC}$ & $28.34 \mathrm{~N}, 91.26 \mathrm{~W}$ & $7 / 5 / 13$ & $30.09 \mathrm{~N}, 87.49 \mathrm{~W}$ & 290 \\
\hline 14 & 132 & $\mathrm{~F}$ & $8 / 24 / 13$ & $\mathrm{NC}$ & $28.86 \mathrm{~N}, 85.63 \mathrm{~W}$ & $9 / 19 / 13$ & $28.99 \mathrm{~N}, 85.54 \mathrm{~W}$ & 26 \\
\hline 15 & 217 & $M$ & $2 / 8 / 14$ & $\mathrm{NC}$ & $28.24 \mathrm{~N}, 89.36 \mathrm{~W}$ & $6 / 28 / 14$ & $28.84 \mathrm{~N}, 89.20 \mathrm{~W}$ & 140 \\
\hline 16 & 179 & $M$ & $2 / 8 / 14$ & $\mathrm{NC}$ & $28.24 \mathrm{~N}, 89.36 \mathrm{~W}$ & $6 / 19 / 14$ & $28.34 \mathrm{~N}, 90.33 \mathrm{~W}$ & 131 \\
\hline 17 & 183 & $M$ & $2 / 9 / 14$ & $\mathrm{NC}$ & $28.64 \mathrm{~N}, 89.56 \mathrm{~W}$ & $4 / 18 / 14$ & $28.56 \mathrm{~N}, 89.37 \mathrm{~W}$ & 68 \\
\hline 18 & 166 & $M$ & $2 / 9 / 14$ & NC & $28.24 \mathrm{~N}, 89.36 \mathrm{~W}$ & $5 / 17 / 14$ & $29.86 \mathrm{~N}, 86.00 \mathrm{~W}$ & 97 \\
\hline 19 & 198 & $M$ & $2 / 9 / 14$ & $\mathrm{NC}$ & $28.24 \mathrm{~N}, 89.36 \mathrm{~W}$ & $6 / 28 / 14$ & $28.24 \mathrm{~N}, 90.25 \mathrm{~W}$ & 139 \\
\hline 20 & 154 & $M$ & $2 / 19 / 14$ & $\mathrm{NC}$ & $28.63 \mathrm{~N}, 89.55 \mathrm{~W}$ & $12 / 18 / 14$ & $28.62 \mathrm{~N}, 89.59 \mathrm{~W}$ & 302 \\
\hline 21 & 158 & $M$ & $2 / 19 / 14$ & $\mathrm{NC}$ & $28.63 \mathrm{~N}, 89.55 \mathrm{~W}$ & $4 / 22 / 15$ & $28.55 \mathrm{~N}, 89.75 \mathrm{~W}$ & 427 \\
\hline 22 & 118 & $M$ & $5 / 5 / 14$ & $\mathrm{NC}$ & $28.87 \mathrm{~N}, 90.22 \mathrm{~W}$ & $5 / 29 / 14$ & $28.86 \mathrm{~N}, 89.95 \mathrm{~W}$ & 24 \\
\hline 23 & 128 & $\mathrm{~F}$ & $5 / 6 / 14$ & $\mathrm{NC}$ & $28.84 \mathrm{~N}, 89.33 \mathrm{~W}$ & $5 / 25 / 14$ & $28.89 \mathrm{~N}, 89.31 \mathrm{~W}$ & 19 \\
\hline 24 & 177 & $\mathrm{~F}$ & $5 / 7 / 14$ & $\mathrm{NC}$ & $28.53 \mathrm{~N}, 89.33 \mathrm{~W}$ & $7 / 4 / 14$ & $28.49 \mathrm{~N}, 89.52 \mathrm{~W}$ & 58 \\
\hline 25 & 181 & $M$ & $8 / 16 / 14$ & $\mathrm{NC}$ & $28.75 \mathrm{~N}, 90.09 \mathrm{~W}$ & $8 / 21 / 14$ & $28.58 \mathrm{~N}, 90.11 \mathrm{~W}$ & 5 \\
\hline 26 & 141 & $M$ & $9 / 8 / 14$ & $\mathrm{NC}$ & $28.68 \mathrm{~N}, 89.51 \mathrm{~W}$ & $4 / 28 / 15$ & $28.68 \mathrm{~N}, 89.76 \mathrm{~W}$ & 232 \\
\hline 27 & 142 & $M$ & $1 / 29 / 15$ & $\mathrm{NC}$ & $29.21 \mathrm{~N}, 88.57 \mathrm{~W}$ & $4 / 30 / 15$ & $28.63 \mathrm{~N}, 90.60 \mathrm{~W}$ & 91 \\
\hline 28 & 200 & $M$ & $1 / 29 / 15$ & $\mathrm{NC}$ & $29.21 \mathrm{~N}, 88.57 \mathrm{~W}$ & $6 / 6 / 15$ & $29.51 \mathrm{~N}, 88.19 \mathrm{~W}$ & 128 \\
\hline 29 & 168 & $M$ & $7 / 14 / 14$ & NW & $27.90 \mathrm{~N}, 96.42 \mathrm{~W}$ & $11 / 5 / 15$ & $26.83 \mathrm{~N}, 96.84 \mathrm{~W}$ & 479 \\
\hline 30 & 220 & $M$ & $7 / 16 / 14$ & NW & $27.90 \mathrm{~N}, 96.43 \mathrm{~W}$ & $8 / 6 / 14$ & $28.37 \mathrm{~N}, 95.83 \mathrm{~W}$ & 21 \\
\hline 31 & 170 & $M$ & $6 / 2 / 15$ & NW & $27.90 \mathrm{~N}, 96.42 \mathrm{~W}$ & $6 / 16 / 15$ & $28.67 \mathrm{~N}, 89.71 \mathrm{~W}$ & 14 \\
\hline 32 & 175 & $M$ & $6 / 2 / 15$ & NW & $27.90 \mathrm{~N}, 96.42 \mathrm{~W}$ & 8/16/16 & $27.33 \mathrm{~N}, 97.18 \mathrm{~W}$ & 441 \\
\hline 33 & 184 & $M$ & $11 / 5 / 15$ & NW & $27.91 \mathrm{~N}, 96.44 \mathrm{~W}$ & $5 / 1 / 16$ & $27.74 \mathrm{~N}, 96.83 \mathrm{~W}$ & 257 \\
\hline
\end{tabular}

Deployment regions include northeast (NE), north-central (NC), and northwest (NW) Gulf of Mexico.

were females. Mean size at the time of tagging was $159.4 \mathrm{~cm}$ FL $( \pm 30.6 \mathrm{~cm} \mathrm{SD})$ ranging from 102 to $220 \mathrm{~cm}$ FL. Tagging activities occurred over a 4-year period from 2012 to 2015 with a mean number of days at liberty of 146 days $( \pm 139.7 \mathrm{SD})$ ranging from 5 to 479 total days until the tag stopped communicating. Four tags communicated over one full year, five additional tags for over six months, and seven more tags for over four months with a total of 4,543 days of communication among the 33 total tagged sharks (Table 1).

\section{Space Use}

Movement patterns of scalloped hammerheads tagged over the northern GOM continental shelf showed a wide range of movement tracks with limited long-distance dispersal (Figures 1A,B). Core use area $(50 \% \mathrm{KDE})$ sizes for scalloped hammerheads were relatively small $\left(9,159 \pm 10,735 \mathrm{~km}^{2}\right.$; mean \pm SD; Figure $\mathbf{1 A}$ and Table 2). MSDs to centroids and
LIs indicated site fidelity in nearly half (MSD: 65\%, LI: 50\%) of tagged scalloped hammerheads (Table 2). Core area size was not significantly related to sex (Kruskal-Wallis test; $H=0.852$, $p=0.356)$ or shark size $\left(F_{1,24}=0.138, p=0.714\right)$. Though no statistically significant relationship was found between sex and horizontal distribution, male shark detections were located across the continental shelf primarily in depths less than $200 \mathrm{~m}$, whereas detections of female sharks were concentrated at the $200 \mathrm{~m}$ isobaths and deeper (Figure 1B).

\section{Habitat Modeling}

The final model describing the influence of environmental variables on the presence of scalloped hammerheads in the northern GOM had an AIC of 3,153 and DE of 33.5\%. Seven of the eight environmental variables were retained in the final model: chl $a$, salinity, SSHA, depth, bathymetric slope, distance to artificial structure, and distance to hard-bottom 


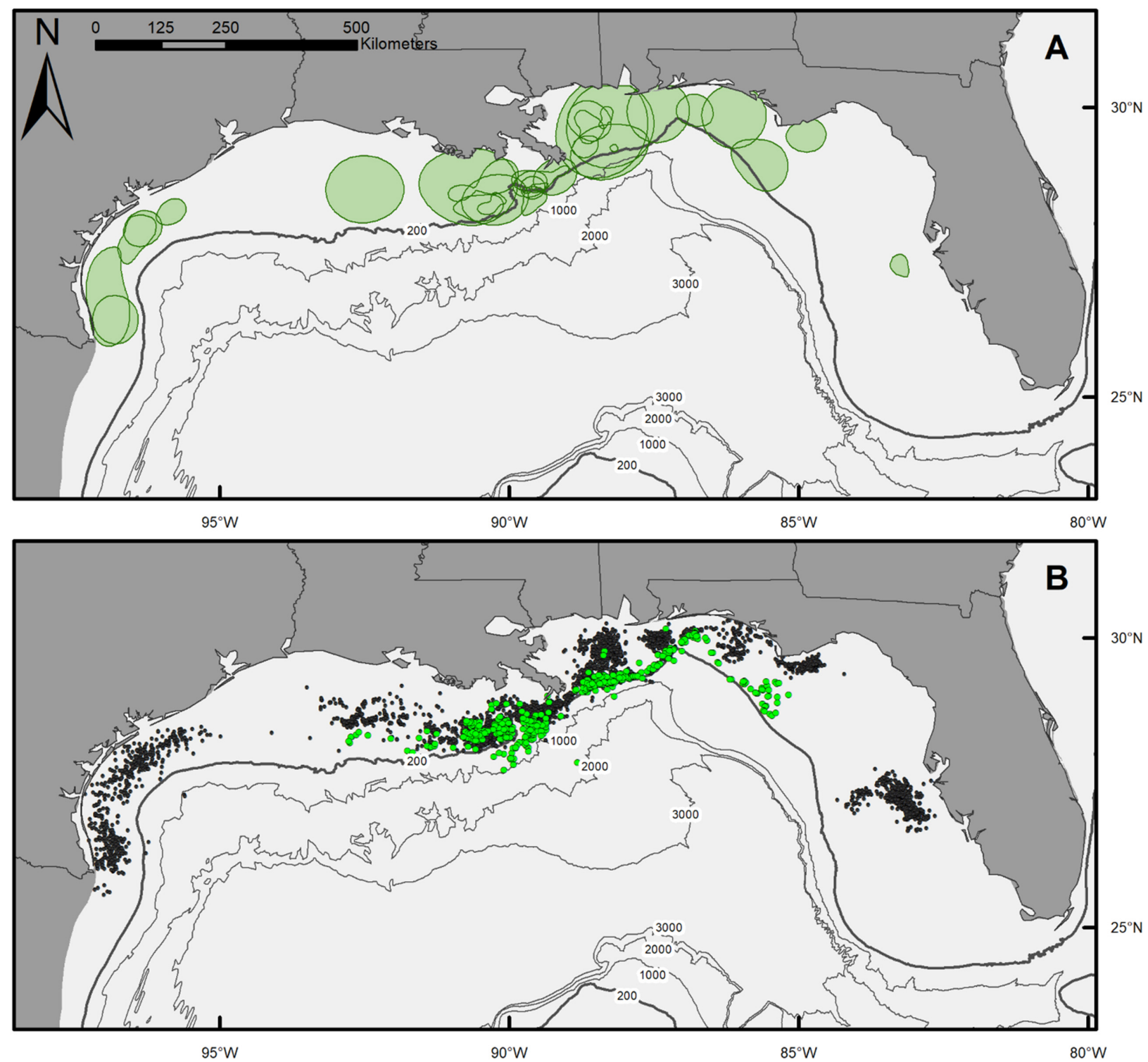

FIGURE 1 | (A) Map of 50\% kernel density estimates (KDE) for individual scalloped hammerheads across the northern Gulf of Mexico. (B) Map of SPOT tag detections of male (black circles) and female (green circles) scalloped hammerheads.

habitat. The most influential environmental variables according to $\triangle \mathrm{AIC}$ were depth $(\triangle \mathrm{AIC}=278.8)$, distance to artificial habitat $(\triangle \mathrm{AIC}=265.1)$, and $\mathrm{chl} a$ concentration $(\Delta \mathrm{AIC}=55.8$; Supplementary Table S1). The same three variables were most influential according to $\triangle \mathrm{DE}$. Response plots indicated that scalloped hammerhead presence increased at depths shallower than 1,500 $\mathrm{m}$ (Figure 2) in close proximity to both artificial and hard-bottom habitat. The presence of scalloped hammerheads was also greatest in waters with low chl a concentrations $\left(\sim 0-4 \mathrm{mg} \mathrm{m}^{-3}\right)$, moderate salinities (33-35.5), and neutral SSHA ( $-0.05-0 \mathrm{~cm}$; Figure 2). Habitat suitability for scalloped hammerheads was predicted to be very high on the mid to outer continental shelf of the GOM inside the $200 \mathrm{~m}$ isobath (Figure 3). Habitat suitability decreased in most nearshore areas (moderate to suitable) with the exception of the NC GOM offshore of Mobile Bay, Alabama to Cape San Blas, Florida, and south Texas, where highly suitable habitat spanned the continental shelf.

\section{State-Space Modeling}

First difference correlated random walk switching modeling identified behavioral switches in two scalloped hammerheads (Fish ID 4 and 28, Figures 4, 5). Both sharks spent the majority of the time making area-restricted movements centralized in two patches separated by a distance of $\sim 350 \mathrm{~km}$ (Figures 5A,B). Both sharks exhibited a small number of switches from area-restricted movement to transiting movement when moving between these patches and across the Mississippi River plume. Another individual scalloped hammerhead (Fish ID 12, Figure 5C) made 

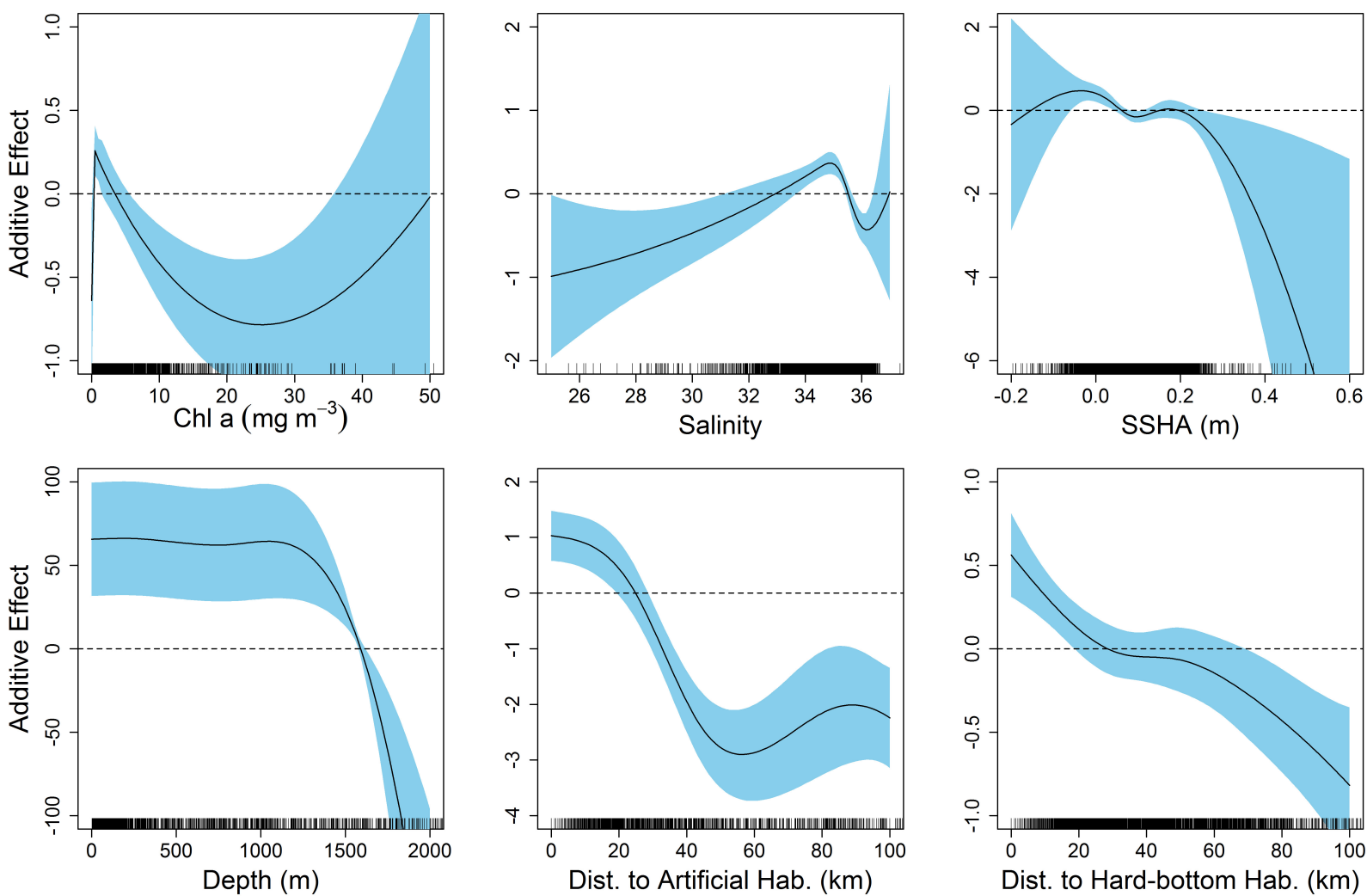

FIGURE 2 | Response plots from generalized additive model (GAM) of environmental variables relative to the presence-absence of scalloped hammerheads throughout the northern Gulf of Mexico.

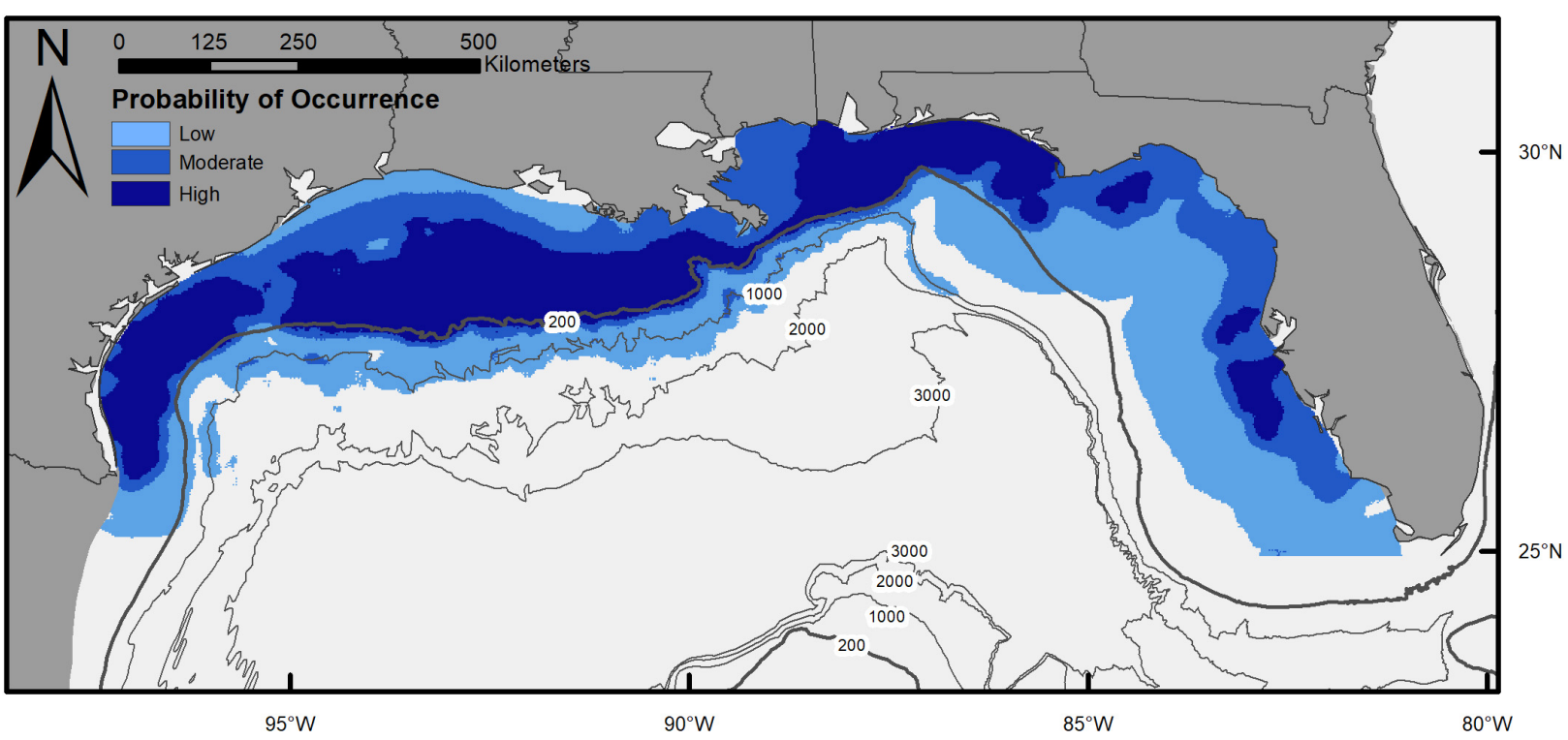

FIGURE 3 | Map of habitat suitability for scalloped hammerheads across the northern Gulf of Mexico, based on generalized additive model of shark presence-absence and environmental variables (chlorophyll a, salinity, sea surface height anomaly, depth, distance to artificial structure, and distance to hard bottom habitat). 
TABLE 2 | Total number of detection days, percent of days at liberty when a daily detection occurred, and summary statistics for site fidelity analysis using mean square distance (MSD) from center of activity and linearity index (LI) of scalloped hammerheads $(n=26)$.

\begin{tabular}{|c|c|c|c|c|c|c|c|c|c|}
\hline \multirow[t]{2}{*}{ Fish ID } & \multirow{2}{*}{$\begin{array}{c}\text { Detection } \\
\text { days }\end{array}$} & \multirow{2}{*}{$\begin{array}{c}\% \text { days } \\
\text { detected }\end{array}$} & \multicolumn{3}{|c|}{ MSD from center of activity } & \multicolumn{3}{|c|}{ Linearity Index } & \multirow{2}{*}{$\begin{array}{c}50 \% \mathrm{KDE} \\
\left(\mathrm{km}^{2}\right)\end{array}$} \\
\hline & & & MSD value & MSD $95 \%$ Cl & MSD site fidelity & LI value & LI $95 \%$ Cl & LI site fidelity & \\
\hline 1 & 95 & 49 & 1.67 & $1.36-8.52$ & FALSE & 0.03 & $0.01-0.16$ & FALSE & $25,296.5$ \\
\hline 2 & 20 & 23 & 0.09 & $0.19-1.56$ & TRUE & 0.15 & $0.06-0.47$ & FALSE & $1,893.65$ \\
\hline 3 & 34 & 100 & 0.59 & $0.14-1.75$ & FALSE & 0.11 & $0.01-0.13$ & FALSE & $4,355.83$ \\
\hline 4 & 98 & 66 & 4.40 & $1.01-7.94$ & FALSE & 0.02 & $0.03-0.21$ & TRUE & $41,932.36$ \\
\hline 5 & 50 & 67 & 0.03 & $0.08-0.67$ & TRUE & 0.01 & $0.02-0.19$ & TRUE & 869.11 \\
\hline 6 & 6 & 21 & NA & NA & NA & NA & NA & NA & NA \\
\hline 7 & 12 & 21 & NA & NA & NA & NA & NA & NA & NA \\
\hline 8 & 172 & 37 & 0.03 & $1.59-9.99$ & TRUE & 0.00 & $0.02-0.24$ & TRUE & 187.62 \\
\hline 9 & 10 & 33 & NA & NA & NA & NA & NA & NA & NA \\
\hline 10 & 20 & 30 & 0.24 & $0.35-2.04$ & TRUE & 0.04 & $0.04-0.55$ & FALSE & $5,659.08$ \\
\hline 11 & 38 & 29 & 0.09 & $0.23-2$ & TRUE & 0.06 & $0.05-0.32$ & TRUE & $2,772.51$ \\
\hline 12 & 117 & 97 & 0.09 & $0.87-6.91$ & TRUE & 0.01 & $0-0.1$ & FALSE & $1,321.67$ \\
\hline 13 & 77 & 27 & 1.81 & $0.5-4.24$ & FALSE & 0.11 & $0.01-0.16$ & FALSE & $15,269.51$ \\
\hline 14 & 11 & 42 & 0.59 & $0.22-2.02$ & FALSE & 0.02 & 0.03-0.39 & TRUE & $13,411.44$ \\
\hline 15 & 35 & 25 & 0.64 & $3.42-30.4$ & TRUE & 0.03 & $0.04-0.63$ & TRUE & $5,201.22$ \\
\hline 16 & 58 & 44 & 0.24 & $0.48-3.33$ & TRUE & 0.03 & $0.02-0.18$ & FALSE & $4,215.05$ \\
\hline 17 & 22 & 32 & 0.18 & $0.17-1.44$ & TRUE & 0.04 & $0.09-0.56$ & TRUE & $1,828.1$ \\
\hline 18 & 36 & 37 & 1.50 & $0.27-2.51$ & FALSE & 0.21 & $0.03-0.28$ & FALSE & $13,525.99$ \\
\hline 19 & 66 & 47 & 0.05 & $0.39-3.85$ & TRUE & 0.03 & $0.01-0.17$ & FALSE & $1,378.55$ \\
\hline 20 & 67 & 22 & 0.02 & $0.13-1.34$ & TRUE & 0.00 & $0.01-0.2$ & TRUE & 422.75 \\
\hline 21 & 36 & 8 & 0.01 & $0.03-0.34$ & TRUE & 0.03 & $0.02-0.2$ & FALSE & 177.17 \\
\hline 22 & 11 & 46 & 0.24 & $0.14-1.31$ & FALSE & 0.04 & $0.04-0.51$ & TRUE & $5,802.86$ \\
\hline 23 & 4 & 21 & NA & NA & NA & NA & NA & NA & NA \\
\hline 24 & 24 & 41 & 0.08 & $0.08-0.7$ & TRUE & 0.02 & $0.01-0.28$ & FALSE & $2,113.86$ \\
\hline 25 & 3 & 60 & NA & NA & NA & NA & NA & NA & NA \\
\hline 26 & 31 & 13 & 0.15 & $0.11-0.96$ & FALSE & 0.03 & $0.02-0.29$ & FALSE & $3,657.9$ \\
\hline 27 & 9 & 10 & 1.13 & $1.62-9.82$ & TRUE & 0.20 & $0.07-0.75$ & FALSE & $24,858.13$ \\
\hline 28 & 58 & 45 & 3.19 & $1.37-13.9$ & FALSE & 0.01 & $0.05-0.29$ & TRUE & $29,474.49$ \\
\hline 29 & 227 & 47 & 0.86 & $1.26-9.91$ & TRUE & 0.02 & $0.02-0.16$ & TRUE & $15,999.75$ \\
\hline 30 & 12 & 57 & NA & NA & NA & NA & NA & NA & NA \\
\hline 31 & 13 & 93 & NA & NA & NA & NA & NA & NA & NA \\
\hline 32 & 141 & 32 & 0.76 & $1.28-7.68$ & TRUE & 0.03 & $0.02-0.25$ & TRUE & $11,604.7$ \\
\hline 33 & 108 & 42 & 0.19 & $0.5-4.32$ & TRUE & 0.02 & $0.02-0.21$ & TRUE & $4,908.03$ \\
\hline
\end{tabular}

Models were only run on individual sharks with at least 20 location estimates (NA indicates individuals without site fidelity estimates). KDE, kernel density estimate.

directed movements $\left(b_{t}<1.5\right)$ toward and along the shoreline of the Florida Panhandle for $\sim 7$ days after tagging, before making less directionally persistent movements $\left(b_{t}>1.5\right)$ over an area of $1,280 \mathrm{~km}^{2}$ for $\sim 30$ days. With the exception of two scalloped hammerheads (Fish ID 4 and 28), values of $b_{t}$ for tagged scalloped hammerheads did not meet criteria for classification into distinct behavioral modes (e.g., Fish ID 12). Non-switching (DCRW) models run for individual scalloped hammerheads did not converge for three sharks (Fish ID 2, 22 , 27). Mean correlated random walk $(\gamma)$ estimates from DCRW models on scalloped hammerheads indicated sharks typically followed uncorrelated random walk (highly tortuous, area-restricted) movements $(\gamma=0.08 \pm 0.09$ mean \pm SD). No relationship was found between shark sex, size (FL), or random walk index.

\section{DISCUSSION}

Knowledge of movement patterns of marine apex predators is essential when attempting to understand connectivity within and across ocean basins for conservation and management efforts. In our study, scalloped hammerhead distribution was primarily restricted to the continental shelf, though track data revealed some cross-shelf movements. Duncan et al. (2006) determined population genetic structure of scalloped hammerheads was substantial for a large marine predator, and that restricted dispersal over deep open ocean habitat may be the primary driver, but found high connectivity and dispersal across continuous coastlines along continental shelves. Tagging studies have found similar overall patterns of limited long-distance movement for this species (Kohler and Turner, 2001); however, individuals are 


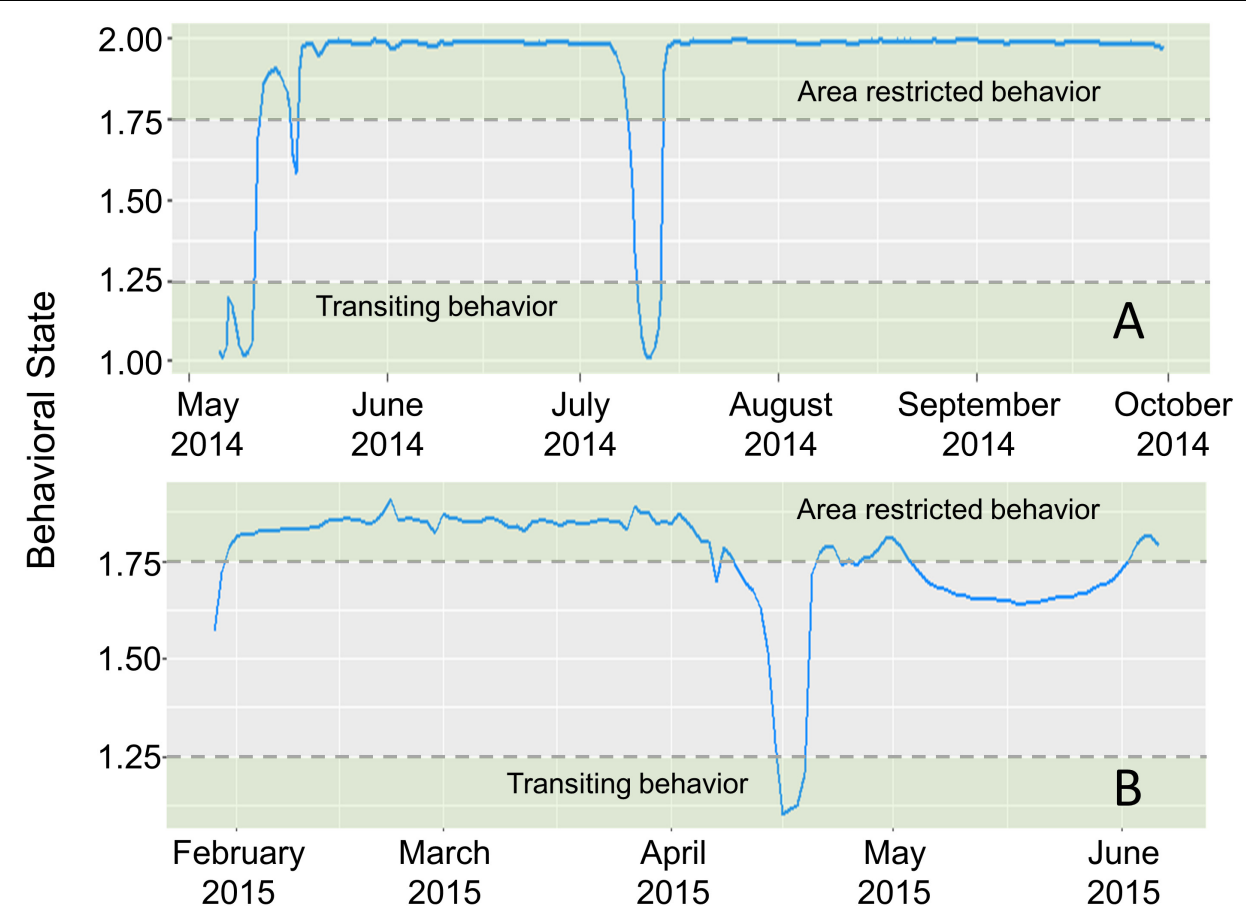

FIGURE 4 | Time series of estimated mean behavioral state (blue line) for scalloped hammerheads ID4 (A) and ID28 (B), estimated in a first-difference correlated random walk switching model. Dashed horizontal lines indicate thresholds for defining behavioral states (green shaded areas) (area-restricted behavior: > 1.75, transiting behavior: < 1.25).

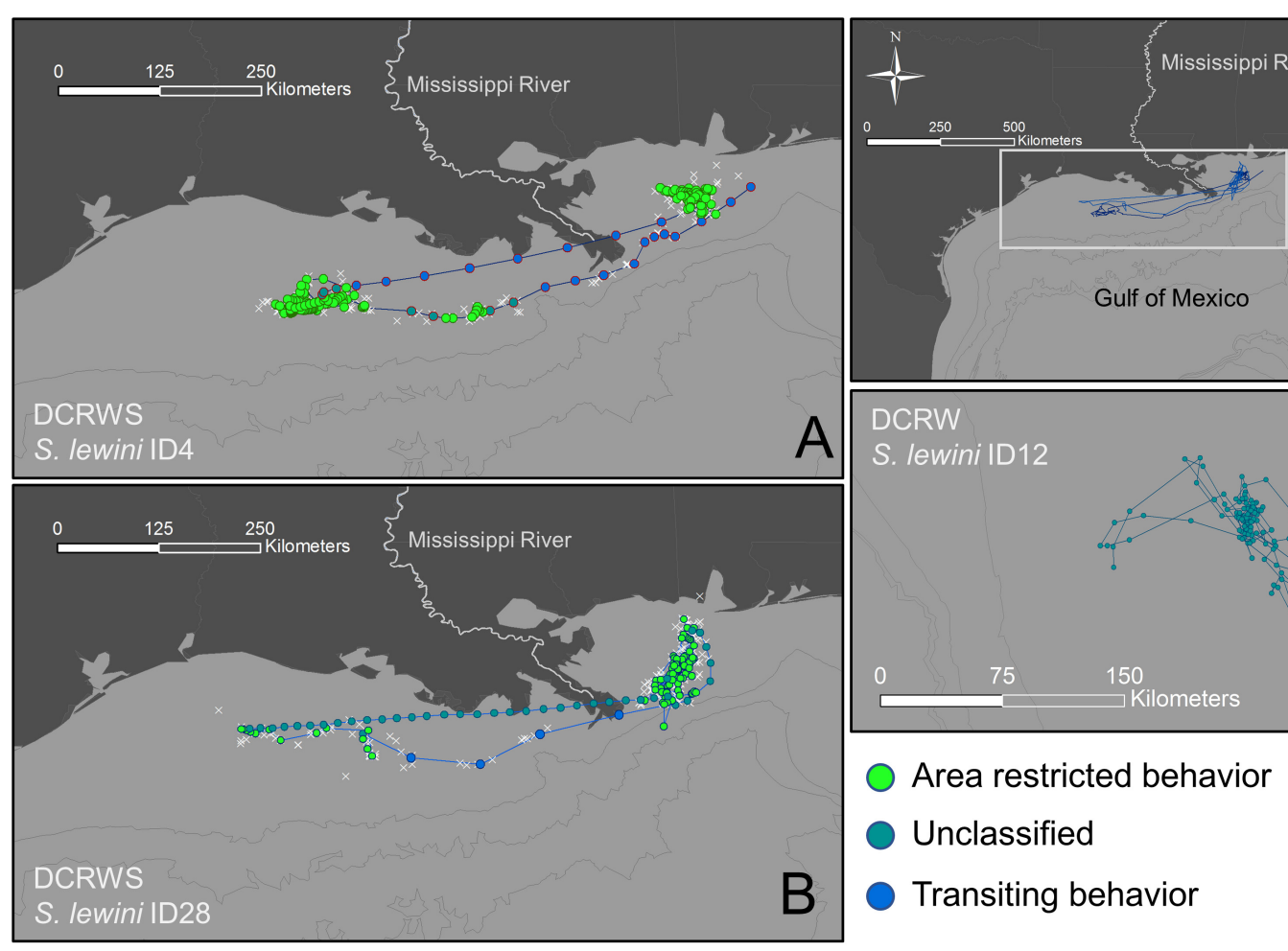

FIGURE 5 | Tracks for scalloped hammerheads ID4 (A), ID28 (B), and ID12 (C) showing observed (white crosses) locations and estimated (filled circles) locations from first-difference correlated random walk switching $(\mathbf{A}, \mathbf{B})$ and first-difference correlated random walk (C) models. 
capable of extensive movements ( $>1,000 \mathrm{~km}$; Kohler and Turner, 2001; Bessudo et al., 2011). Scalloped hammerhead movements were monitored for just over a single year ( $479 \mathrm{~d}$ maximum, Table 1) making it difficult to assess long-term movement in this study. There was little indication of seasonal patterns in habitat use as demonstrated for other species of elasmobranchs in the northern GOM (Drymon et al., 2010; Bethea et al., 2015). Nevertheless, results show restricted movement across the continental shelf with limited evidence of open ocean habitat use beyond the shelf edge.

Though only five females were tagged in this study, evidence suggests these individuals more frequently use shelf-edge (>200 $\mathrm{m}$ isobath) areas in contrast to shallower depths along the mid-shelf used by males. While this is in stark contrast to the presence of periodically high abundances of neonates in multiple coastal areas across the GOM (Hueter and Tyminski, 2007; Bethea et al., 2015), additional tagging studies that target mature females may better reveal inshore-offshore habitat connectivity as well as potential areas of parturition. Sex-specific movement patterns and segregation are relatively common in elasmobranchs (Sims, 2005), and sexual segregation has been reported for scalloped hammerheads in the GOM (Branstetter, 1987). Klimley (1987) found females in the Gulf of California moved further offshore at a smaller size than males, and provided evidence that this strategy may be to rapidly increase in size to reach sexual maturity due to enhanced prey availability. Size and sex segregated populations may be disproportionately affected by interactions with fisheries operating in specific habitats or regions. In the GOM, the majority of reported fishing mortality of scalloped hammerheads occurs in coastal-shelf BLL fisheries, with comparatively few scalloped hammerheads being taken in other sectors (e.g., pelagic longline; Miller et al., 2014). If scalloped hammerheads that most frequently interact with BLL sets in coastal waters are presumed to be males or sexually immature, GOM populations may not necessarily face the potential risk of mate limitation resulting from the loss of larger females.

Habitat preferences of scalloped hammerheads appeared to be primarily driven by bathymetric features such as depth and bottom type, rather than dynamic oceanographic processes (e.g., SST and SSHA). The preference for mid-shelf or shelf edge habitats $(<200 \mathrm{~m}$ depth $)$ is consistent with aforementioned fisheries dependent data that indicate this species is rarely captured in oceanic waters of the GOM (Miller et al., 2014). The positive association of tagged scalloped hammerheads with natural hard-bottom habitat in the current study is not surprising given that large schools are observed annually at mid-shelf and shelf edge banks (e.g., Flower Garden Banks) in the northern GOM (Childs, 2001). Bathymetric features such as seamounts and associated currents are thought to enhance prey availability to scalloped hammerheads (Klimley, 1993; Hearn et al., 2010; Ketchum et al., 2014a), and thus natural reefs and hard-bottom outcroppings may be important habitats or foraging areas for this species in the GOM. Still, scalloped hammerheads in the current study were more closely linked to artificial habitats, particularly (standing and toppled) oil and gas platforms. Oil and gas platforms are productive habitats (Claisse et al., 2014) that provide structure throughout the water column, and often hold higher fish densities compared to natural habitats (Streich et al., 2017). Given the high fish densities and number of such structures in the northern GOM $(>2,000)$, it is likely that large predators such as scalloped hammerheads frequent oil and gas platforms to increase foraging opportunities. While habitat use in this study was primarily associated with bathymetric features, scalloped hammerheads were also negatively associated with high chlorophyll $a$, suggesting that this species may avoid nearshore areas of high nutrient input (e.g., Mississippi River plume, low salinity estuaries). This finding was supported by movement patterns from our switching models that suggest sharks avoided surface waters of the Mississippi River plume. Likewise, our habitat suitability maps indicated that habitat suitability was highest from the mid to outer shelf and over nearshore areas with relatively low freshwater inflow (NW Florida, south Texas). While other oceanographic variables contributed very little to our final models, it remains a possibility that oceanographic drivers may yet influence the movements of female, and larger, scalloped hammerheads, which are presumed to spend a greater proportion of time in off-shelf pelagic habitats with fewer bathymetric features.

The majority of tagged scalloped hammerheads displayed area-restricted movements, with limited evidence of behavioral switches to transiting movements. Several potential factors have been suggested to influence the site fidelity, home range size, and proportion of time a predator spends engaged in area-restricted searching versus transiting movements, including proximate cues such as prey abundance and inter-specific competition (Kittle et al., 2016), and ultimate drivers such as reproductive success (Patrick and Weimerskirch, 2017). The DCRWS modeling identified behavioral switches between transiting and arearestricted movements in two scalloped hammerheads. Though these switches did not appear to correspond to abiotic factors investigated, behavioral switches for both scalloped hammerheads were observed in proximity to the Mississippi River plume suggesting this feature may not act as a barrier for longitudinal movement of this species. The median detection interval for both sharks was less than $2 \mathrm{~h}$, while movements across the Mississippi River plume were associated with gaps in detection greater than 5 days, similar to a lack of detections found around this plume for great hammerheads (Sphyrna mokarran; Drymon and Wells, 2017). Vertical stratification of the water column is common where the Mississippi River meets the GOM (Androulidakis et al., 2015), and prolonged intervals observed between SPOT transmissions in this area suggest that sharks avoided surface waters when traversing the plume, potentially in response to vertical gradients in environmental conditions (e.g., salinity, temperature, and dissolved oxygen) or prey availability. At the Mississippi River mouth, seasonal hypoxia begins forming in the spring and persists throughout the summer (Bianchi et al., 2010). Shark ID 4 exhibited transiting behavior across the "dead zone" regions during the summer when hypoxia is most severe, possibly suggesting avoidance of low oxygen water. Alternatively, as hypoxia can aggregate prey near the edges of the dead zone (Craig, 2012), it is possible the sharks are experiencing enhanced foraging on stressed prey in hypoxic environments, as 
demonstrated in teleost fish (Pihl et al., 1992; Long and Seitz, 2008). A satellite tagged scalloped hammerhead in the Gulf of California made deep dives exceeding $250 \mathrm{~m}$ into severely hypoxic water that was potentially related to pursuing deepwater squid prey (Jorgensen et al., 2009). Thus, if scalloped hammerheads are able to tolerate low oxygen conditions, they may experience an energetic tradeoff with enhanced prey consumption. Given the rate $(\sim 3 \mathrm{~km} / \mathrm{h})$ at which sharks traversed the Mississippi River plume (when movements were classified as transiting behavior), it is likely that the DCRWS model did not identify true behavioral switches, but rather sharks simply continued to make area-restricted movements while tags were submerged and unable to transmit positional data. Alternatively, it is possible these sharks made transiting movements that were not identified by DCRWS models. Nevertheless, behavioral state cannot be accurately inferred for movements made over spatiotemporal scales smaller than those detectable by the tags in this study, due to positional error of tags (poor location classes), or tags being submerged.

Performance based on tag type can be species-specific and this study found fin-mounted SPOT tags appear to be a viable option to obtain daily position estimates of scalloped hammerheads, owing to what is likely a considerable amount of time spent at the surface. In contrast, a recent study by Drymon and Wells (2017) used a double tagging approach on great hammerheads in the GOM and found fin-mounted SPOT tags were a poor choice, despite known use of surface waters by this species (Queiroz et al., 2016). A similar study on juvenile smooth hammerheads (Sphyrna zygaena) also had limited success using fin-mounted SPOT tags in New Zealand (Francis, 2016). Several studies examining movement of scalloped hammerheads have used different tag technology including acoustic telemetry (Klimley, 1993; Bessudo et al., 2011; Ketchum et al., 2014a,b) and PAT tags (Jorgensen et al., 2009; Hoffmayer et al., 2013). The goal of this study was not to evaluate tag type; however, our results propose the utility of fin-mounted SPOT tags to provide information on habitat use for scalloped hammerheads in this region of the GOM.

Results of this study provide valuable movement information needed to properly conserve this species and to guide fishery management. Similar findings for the great hammerhead were found by Guttridge et al. (2017) highlighting the need for local conservation and management due to the seasonal residency and site fidelity of this species in the southeastern United States and Bahamas. A recent ERA (Miller et al., 2014) evaluated the six distinct population segments of scalloped hammerheads and determined that the NW Atlantic and GOM stock as well as the Central Pacific stock have declined to relatively low levels of abundance but were at low risk of current extinction. In contrast, the Central and Southwest Atlantic stock and the Indo-West Pacific stock were at moderate risk of extinction and the Eastern Atlantic and Eastern Pacific stocks were at high risks of extinction. Findings from this study provide important information on movement of this species in the GOM and highlight the restricted use of continental shelf habitat and resident behavior that will need to be incorporated in future stock assessments and extinction risk analyses. Areas where concentrated fishing effort is relatively high may have significant impacts on this species given the sex-specific differences in habitat use and deserves careful consideration for future conservation measures.

\section{ETHICS STATEMENT}

Sharks tagged from 2014 and beyond were approved by the Institutional Animal Care and Use Committee (IACUC) reference number 009413 at Texas A\&M University. Sharks tagged prior to 2014 did not require approval in accordance with the Louisiana Department of Wildlife and Fisheries (LDWF) and National Marine Fisheries Service (NMFS).

\section{AUTHOR CONTRIBUTIONS}

All authors contributed to the design and implementation of the research. RW, TT, and MD contributed to the analysis of the results. RW led writing of the manuscript with assistance from all authors.

\section{FUNDING}

The open access publishing fees for this article have been covered by the Texas A\&M University Open Access to Knowledge Fund (OAKFund), supported by the University Libraries and the Office of the Vice President for Research.

\section{ACKNOWLEDGMENTS}

We would like to thank A. Kroetz, E. Seubert, T. Guoba, J. Whitman, and members of the Shark Biology and Fisheries Science Lab at Texas A\&M University at Galveston, Louisiana Department of Wildlife and Fisheries (LDWF) field crew, the Center for Sportfish Science, and Conservation Harte Research Institute at Texas A\&M University - Corpus Christi for field assistance. We would also like to thank W. Mobley and $\mathrm{H}$. Walters for their assistance with geospatial analyses along with the captain and crew of the NOAA Ship Oregon II, K. Hannah, L. Jones, and C. Jones for their assistance in the field. Special thanks to the Aquarium at Moody Gardens, LDWF, the McDaniel Charitable Foundation, and the Texas State Aquarium for support in providing satellite tags.

\section{SUPPLEMENTARY MATERIAL}

The Supplementary Material for this article can be found online at: $\quad$ https://www.frontiersin.org/articles/10.3389/fmars.2018. 00321/full\#supplementary-material

FIGURE S1 | Locations of standing oil and gas platforms used in this study. Data were obtained from the Bureau of Ocean Energy Management (BOEM). 
TABLE S1 | Environmental variables retained in the final generalized additive model (GAM) describing the presence/absence of tagged scalloped hammerheads. Model fit was assessed with Akaike's information criterion (AIC)

\section{REFERENCES}

Aarts, G., MacKenzie, M., McConnell, B., Fedak, M., and Matthiopoulos, J. (2008). Estimating space-use and habitat preference from wildlife telemetry data. Ecography 31, 140-160. doi: 10.1111/j.2007.0906-7590.05236.x

Abercrombie, D. L., Clarke, S. C., and Shivji, M. S. (2005). Global-scale genetic identification of hammerhead sharks: application to assessment of the international fin trade and law enforcement. Conserv. Genet. 6, 775-788. doi: 10.1007/s10592-005-9036-2

Ajemian, M. J., Jose, P., Froeschke, J., Wildhaber, M. L., and Stunz, G. W. (2016). Was everything bigger in Texas? Characterization and trends of a land-based recreational shark fishery. Mar. Coast. Fish. 8, 553-556. doi: 10.1080/19425120. 2016.1227404

Akaike, H. (1974). A new look at the statistical model identification. IEEE Trans Automat. Control 19, 716-723. doi: 10.1109/TAC.1974.1100705

Androulidakis, Y. S., Kourafalou, V. H., and Schiller, R. V. (2015). Process studies on the evolution of the Mississippi River plume: impact of topography, wind and discharge conditions. Cont. Shelf Res. 107, 33-49. doi: 10.1016/j.csr.2015. 07.014

Baum, J. K., and Blanchard, W. (2010). Inferring shark population trends from generalized linear mixed models of pelagic longline catch and effort data. Fish Res. 102, 229-239. doi: 10.1016/j.fishres.2009.11.006

Becker, J. J., Sandwell, D. T., Smith, W. H. F., Braud, J., Binder, B., Depner, J., et al. (2009). Global bathymetry and elevation data at 30 arc seconds resolution: SRTM30_PLUS. Mar. Geod. 32, 355-371. doi: 10.1080/01490410903297766

Bessudo, S., Soler, G. A., Klimley, A. P., Ketchum, J. T., Hearn, A., and Arauz, R. (2011). Residency of the scalloped hammerhead shark (Sphyrna lewini) at Malpelo Island and evidence of migration to other islands in the Eastern Tropical Pacific. Environ. Biol. Fishes 91, 165-176. doi: 10.1007/s10641-0119769-3

Bethea, D. M., Ajemian, M. J., Carlson, J. K., Hoffmayer, E. R., Imhoff, J. L., Grubbs, R. D., et al. (2015). Distribution and community structure of coastal sharks in the northeastern Gulf of Mexico. Environ. Biol. Fish. 98, 1233-1254. doi: 10.1007/s10641-014-0355-3

Bianchi, T. S., DiMarco, S. F., Cowan, J. H., Hetland, R. D., Chapman, P., Day, J. W., et al. (2010). The science of hypoxia in the Northern Gulf of Mexico: a review. Sci. Total Environ. 408, 1471-1484. doi: 10.1016/j.scitotenv.2009.11.047

Biggs, D. C. (1992). Nutrients, plankton, and productivity in a warm-core ring in the western Gulf of Mexico. J. Geophys. Res. 97, 2143-2154. doi: 10.1029/ 90JC02020

Block, B. A., Dewar, H., Blackwell, S. B., Williams, T. D., Prince, E. D., Farwell, C. J., et al. (2001). Migratory movements, depth preferences, and thermal biology of Atlantic bluefin tuna. Science 293, 1310-1314. doi: 10.1126/science.10 61197

Block, B. A., Jonsen, I. D., Jorgensen, S. J., Winship, A. J., Shaffer, S. A., Bograd, S. J., et al. (2011). Tracking apex marine predator movements in a dynamic ocean. Nature 475, 86-90. doi: 10.1038/nature10082

Branstetter, S. (1987). Age, growth and reproductive biology of the silky shark, Carcharhinus falciformis, and the scalloped hammerhead, Sphyrna lewini, from the northwestern Gulf of Mexico. Environ. Biol. Fish. 19, 161-173. doi: 10.1007/ BF00005346

Brill, R. W., Block, B. A., Boggs, C. H., Bigelow, K. A., Freund, E. V., and Marcinek, D. J. (1999). Horizontal movements and depth distribution of large adult yellowfin tuna (Thunnus albacares) near the Hawaiian Islands, recorded using ultrasonic telemetry: implications for the physiological ecology of pelagic fishes. Mar. Biol. 133, 395-408. doi: 10.1007/s002270050478

Buczkowski, B. J., Reid, J. A., Jenkins, C. J., Reid, J. M., Williams, S. J., and Flocks, J. G. (2006). usSEABED: Gulf of Mexico and Caribbean (Puerto Rico and U.S. Virgin Islands) Offshore Surficial Sediment Data Release. Reston, VA: USGS Data Release, 146.

Burnham, K. P., and Anderson, D. R. (2002). Model Selection and Multimodel Inference: A Practical Information-Theoretic Approach. New York: Springer NY. and $\%$ deviance explained (\% DE). The relative importance of each predictor variable to the final model is given as the difference in model $\mathrm{AIC}(\triangle \mathrm{AIC})$ and $\% \mathrm{DE}$ $(\triangle \mathrm{DE})$ if this variable is removed from the final model.

Camhi, M. D., Valenti, S. V., Fordham, S. V., Fowler, S. L., and Gibson, C. (2009). The Conservation Status of Pelagic Sharks and Rays: Report of the IUCN Shark Specialist Group Pelagic Shark red list Workshop. Newbury: IUCN species survival commission shark specialist group.

Chapman, D. D., Pinhal, D., and Shivji, M. S. (2009). Tracking the fin trade: genetic stock identification in western Atlantic scalloped hammerhead sharks Sphyrna lewini. Endanger. Species Res. 9, 221-228. doi: 10.3354/esr 00241

Chesney, E. J., Baltz, D. M., and Thomas, R. G. (2000). Louisiana estuarine and coastal fisheries and habitats: perspectives from a fish's eye view. Ecol. Appl. 10, 350-366. doi: 10.1890/1051-0761(2000)010[0350:LEACFA]2.0.CO;2

Childs, J. (2001). The Occurrence, Habitat Use, and Behavior of Sharks and Rays Associating with Topographic Highs in the Northwestern Gulf of Mexico. M.S. thesis, Texas A\&M University, College Station, TX, 213.

Chin, A., Simpfendorfer, C. A., White, W. T., Johnson, G. J., McAuley, R. B., and Heupel, M. R. (2017). Crossing lines: a multidisciplinary framework for assessing connectivity of hammerhead sharks across jurisdictional boundaries. Sci. Rep. 7:46061. doi: 10.1038/srep46061

Ciannelli, L., Fauchald, P., Chan, K. S., Agostini, V. N., and Dingsor, G. E. (2008). Spatial fisheries ecology: recent progress and future prospects. J. Mar. Syst. 71, 223-236. doi: 10.1016/j.jmarsys.2007.02.031

Claisse, J. T., Pondella, D. J., Love, M., Zahn, L. A., Williams, C. M., Williams, J. P., et al. (2014). Oil platforms off California are among the most productive marine fish habitats globally. Proc. Natl. Acad. Sci. U.S.A. 111, 15462-15467. doi: 10.1073/pnas.1411477111

Clark, S. C., Magnuessen, J. E., Abercrombie, D. L., McAllister, M. K., and Shivji, M. S. (2006). Identification of shark species composition and proportion in the Hong Kong shark fin market based on molecular genetics and trade records. Conserv. Biol. 20, 201-211. doi: 10.1111/j.1523-1739.2005. 00247.x

Compagno, L. V. J. (1984). Sharks of the World. An Annotated and Illustrated Catalogue of Shark Species known to Date. Part 2: Carcharhiniformes. FAO Fish Synop, Vol. 4. Rome: FAO, 251-655.

Cortes, E. (2000). Life history patterns and correlations in sharks. Rev. Fish. Sci. 8, 299-344. doi: 10.1086/698496

Craig, J. K. (2012). Aggregation on the edge: effects of hypoxia avoidance on the spatial distribution of brown shrimp and demersal fishes in the Northern Gulf of Mexico. Mar. Ecol. Prog. Ser. 445, 75-95. doi: 10.3354/meps 09437

Drymon, J. M., Powers, S. P., Dindo, J., Dzwonkowski, B., and Henwood, T. A. (2010). Distributions of sharks across a continental shelf in the northern Gulf of Mexico. Mar. Coast. Fish. 2, 440-450. doi: 10.1577/C09-061.1

Drymon, J. M., and Wells, R. J. D. (2017). Double tagging clarifies postrelease fate of great hammerheads (Sphyrna mokarran). Anim. Biotelem. 5:28. doi: 10.1186/s40317-017-0143-x

Duncan, K. M., and Holland, K. N. (2006). Habitat use, growth rates and dispersal patterns of juvenile scalloped hammerhead sharks Sphyrna lewini in a nursery habitat. Mar. Ecol. Prog. Ser. 312, 211-221. doi: 10.3354/meps31 2211

Duncan, K. M., Martin, A. P., Bowen, B. W., and de Couet, H. G. (2006). Global phylogeography of the scalloped hammerhead shark (Sphyrna lewini). Mol. Ecol. 15, 2239-2251. doi: 10.1111/j.1365-294X.2006.02933.x

Francis, M. P. (2016). Distribution, habitat, and movement of juvenile smooth hammerhead sharks (Sphyrna zygaena) in northern New Zealand. N. Z. J. Mar. Freshwater Res. 50, 506-525. doi: 10.1080/00288330.2016.11 71244

Gallagher, A. J., Serafy, J. E., Cooke, S. J., and Hammerschlag, N. (2014). Physiological stress response, reflex impairment, and survival of five sympatric shark species following experimental capture and release. Mar. Ecol. Prog. Ser. 496, 207-218. doi: 10.3354/meps10490

Gelman, A., and Rubin, D. B. (1992). Inference from iterative simulation using multiple sequences. Stat. Sci. 7, 457-472. doi: 10.1214/ss/1177011136 
Guttridge, T. L., Van Zinnicq Bergmann, M. P. M., Bolte, C., Howey, L. A., Finger, J. S., Kessel, S. T., et al. (2017). Philopatry and regional connectivity of the great hammerhead shark, Sphyrna mokarran in the U.S. and Bahamas. Front. Mar. Sci. 4:3. doi: 10.3389/fmars.2017.00003

Hammerschlag, N., Gallagher, A. J., and Lazarre, D. M. (2011). A review of shark satellite tagging studies. J. Exp. Mar. Biol. Ecol. 398, 1-8. doi: 10.1016/j.jembe. 2010.12.012

Hayes, C. G., Jiao, Y., and Cortes, E. (2009). Stock assessment of scalloped hammerheads in the western North Atlantic Ocean and Gulf of Mexico. N. Am. J. Fish. Manag. 29, 1406-1417. doi: 10.1577/M08-026.1

Hearn, A., Ketchum, J., Klimley, A. P., Espinoza, E., and Penaherrera, C. (2010). Hotspots within hotspots? Hammerhead shark movements around Wolf Island, Galapagos Marine Reserve. Mar. Biol. 157, 1899-1915. doi: 10.1007/s00227010-1460-2

Hoffmayer, E. R., Franks, J. S., Driggers, W. B., and Howey, P. W. (2013). Diel vertical migrations of a scalloped hammerhead, Sphyrna lewini, in the northern Gulf of Mexico. Bull. Mar. Sci. 89, 551-557. doi: 10.5343/bms.2012.1048

Hueter, R. E., and Tyminski, J. P. (2007). "Species-specific distribution and habitat characteristics of shark nurseries in Gulf of Mexico waters off Peninsular Florida and Texas," in Proceedings of the Symposium on Shark Nursery Grounds of the Gulf of Mexico and the East Coast Waters of the United States, Vol. 50, eds C. T. McCandless, N. E. Kohler, and H. L. Pratt, Jr. (Bethesda, MD: American Fisheries Society), 193-223.

Jonsen, I. D., Myers, R. A., and James, M. C. (2007). Identifying leatherback turtle foraging behaviour from satellite telemetry using a switching state-space model. Mar. Ecol. Prog. Ser. 337, 255-264. doi: 10.3354/meps337255

Jorgensen, S. J., Klimley, A. P., and Muhlia-Melo, A. F. (2009). Scalloped hammerhead shark Sphyrna lewini, utilizes deep-water, hypoxic zone in the Gulf of California. J. Fish Biol. 74, 1682-1687. doi: 10.1111/j.1095-8649.2009. 02230.x

Ketchum, J. T., Hearn, A., Klimley, A. P., Espinoza, E., Penaherrera, C., and Largier, J. L. (2014a). Seasonal changes in movements and habitat preferences of the scalloped hammerhead shark (Sphyrna lewini) while refuging near an oceanic island. Mar. Biol. 161, 755-767. doi: 10.1007/s00227-0132375-5

Ketchum, J. T., Hearn, A., Klimley, A. P., Penaherrera, C., Espinoza, E., Bessudo, S., et al. (2014b). Inter-island movements of scalloped hammerhead sharks (Sphyrna lewini) and seasonal connectivity in a marine protected area of the eastern tropical Pacific. Mar. Biol. 161, 939-951. doi: 10.1007/s00227-0142393-y

Kittle, A. M., Bukombe, J. K., Sinclair, A. R. E., Mduma, S. A. R., and Fryxell, J. M. (2016). Landscape-level movement patterns by lions in western Serengeti: comparing the influence of inter-specific competitors, habitat attributes and prey availability. Mov. Ecol. 4:17. doi: 10.1186/s40462-0160082-9

Klimley, A. P. (1987). The determinants of sexual segregation in the scalloped hammerhead shark, Sphyrna lewini. Environ. Biol. Fish. 18, 27-40. doi: 10.1007/ BF00002325

Klimley, A. P. (1993). Highly directional swimming by scalloped hammerhead sharks, Sphyrna lewini, and subsurface irradiance, temperature, bathymetry, and geomagnetic field. Mar. Biol. 117, 1-22. doi: 10.1007/BF00346421

Kohler, N. E., and Turner, P. A. (2001). Shark tagging: a review of conventional methods and studies. Environ. Biol. Fish. 60, 191-223. doi: 10.1023/A: 1007679303082

Kraus, R. T., and Rooker, J. R. (2007). Patterns of vertical habitat use by Atlantic blue marlin (Makaira nigricans) in the Gulf of Mexico. Gulf Caribb. Res. 19, 89-97. doi: 10.18785/gcr.1902.11

Long, W. C., and Seitz, R. D. (2008). Trophic interactions under stress: hypoxia enhances foraging in an estuarine food web. Mar. Ecol. Prog. Ser. 362, 59-68. doi: 10.3354/meps07395

Lowe, C. G. (1996). Kinematics and critical swimming speed of juvenile scalloped hammerhead sharks. J. Exp. Biol. 19, 2605-2610.

McKinney, J. A., Hoffmayer, E. R., Wu, W., Fulford, R., and Hendon, J. M. (2012). Feeding habit of the whale shark Rhincodon typus in the northern Gulf of Mexico determined using species distribution modeling. Mar. Ecol. Prog. Ser. 458, 199-211. doi: 10.3354/meps09777

Miller, M. H., Carlson, J., Cooper, P., Kobayashi, D., Nammack, M., and Wilson, J. (2014). "Status review report: scalloped hammerhead sharks (Sphyrna lewini)," in Proceedings of the Final report to National Marine Fisheries Service, Office of Protected Resources, Silver Spring, MD, 133.

Morgan, A. C., and Burgess, G. H. (2007). At-vessel fishing mortality for six species of sharks caught in the northwest Atlantic and Gulf of Mexico. Gulf Caribb. Res. 19, 123-129. doi: 10.18785/gcr.1902.15

Myers, R. A., and Worm, B. (2003). Rapid worldwide depletion of predatory fish communities. Nature 423, 280-283. doi: 10.1038/nature01610

Oey, L. Y., Ezer, T., and Lee, H. C. (2005). "Loop current, rings and related circulation in the Gulf of Mexico: a review of numerical models and future challenges," in Circulation in the Gulf of Mexico: Observations and Models, eds W. Sturges and A. Lugo-Fernandez (Washington D.C: American Geophysical Union), 31-56.

Patrick, S. C., and Weimerskirch, H. (2017). Reproductive success is driven by local site fidelity despite stronger specialization by individuals for largescale habitat preference. J. Anim. Ecol. 86, 674-682. doi: 10.1111/1365-2656. 12636

Piercy, A. N., Carlson, J. K., Sulikowski, J. A., and Burgess, G. (2007). Age and growth of the scalloped hammerhead shark, Sphyrna lewini, in the north-west Atlantic Ocean and Gulf of Mexico. Mar. Freshw. Res. 58, 34-40. doi: 10.1071/ MF05195

Pihl, L., Baden, S. P., Diaz, R. J., and Schaffner, L. C. (1992). Hypoxia-induced structural changes in the diet of bottom-feeding fish and Crustacea. Mar. Biol. 112, 349-361. doi: 10.1007/BF00356279

Powers, S. P., Fodrie, F. J., Scyphers, S. B., Drymon, J. M., Shipp, R. L., and Stunz, G. W. (2013). Gulf-wide decreases in the size of large coastal sharks documented by generations of fisherman. Mar. Coast. Fish. 5, 93-102. doi: 10.1080/19425120. 2013.786001

Quattro, J. M., Stoner, D. S., Driggers, W. B., Anderson, C. A., Priede, K. A., Hoppmann, E. C., et al. (2006). Genetic evidence of cryptic speciation within hammerhead sharks (genus Sphyrna). Mar. Biol. 148, 1143-1155. doi: 10.1007/ s00227-005-0151-x

Queiroz, N., Humphries, N. E., Mucientes, G., Hammerschlag, N., Lima, F. P., Scales, K. L., et al. (2016). Ocean-wide tracking of pelagic sharks reveals extent of overlap with longline fishing hotspots. Proc. Natl. Acad. Sci. U.S.A. 113, 1582-1587. doi: 10.1073/pnas.1510090113

R Development Core Team (2011). R: A Language and Environment for Statistical Computing. Vienna: R Foundation for Statistical Computing. Available at: http://www.r-project.org

Raftery, A. E., and Lewis, S. M. (1992). [Practical Markov Chain Monte Carlo]: comment: one long run with diagnostics: implementation strategies for Markov Chain Monte Carlo. Stat. Sci. 7, 493-497. doi: 10.1214/ss/1177011143

Richards, W. J., Leming, T., McGowen, M. F., Lamkin, J., and Kelley-Fraga, S. (1989). Distribution of fish larvae in relation to hydrographic features of the Loop Current boundary in the Gulf of Mexico. Rapp. P V Reun. Cons. Int. Explor. Mem. 191, 169-176.

Roberts, J. J., Best, B. D., Dunn, D. C., Treml, E. A., and Halpin, P. N. (2010). Marine geospatial ecology tools: an integrated framework for ecological geoprocessing with ArcGIS, Python, R, MATLAB, and C++. Environ. Model. Softw. 25, 1197-1207. doi: 10.1016/j.envsoft.2010.03.029

Rooker, J. R., Simms, J. R., Wells, R. J. D., Holt, S. A., Holt, G. J., Graves, J. E., et al. (2012). Distribution and habitat associations of billfish and swordfish larvae across mesoscale features in the Gulf of Mexico. PLoS One 7:e34180. doi: 10.1371/journal.pone. 0034180

Ryan, L. A., Meeuwig, J. J., Hemmi, J. M., Collin, S. P., and Hart, N. S. (2015). It is not just size that matters: shark cruising speeds are species-specific. Mar. Biol. 162, 1307-1318. doi: 10.1007/s00227-015-2670-4

Scheffer, M., Carpenter, S., and de Young, B. (2005). Cascading effects of overfishing marine systems. Trends Ecol. Evol. 20, 579-581. doi: 10.1016/j.tree. 2005.08.018

Schlaff, A. M., Heupel, M. R., and Simpfendorfer, C. A. (2014). Influence of environmental factors on shark and ray movement, behaviour and habitat use: a review. Rev. Fish Biol. Fish. 24, 1089-1103. doi: 10.1007/s11160-014-9364-8

Sequeira, A., Mellin, C., Rowat, D., Meekan, M. G., and Bradshaw, C. J. A. (2012). Ocean-scale prediction of whale shark distribution. Divers. Distrib. 18, 504-518. doi: 10.1111/j.1472-4642.2011.00853.x

Signer, J., and Balkenhol, N. (2015). Reproducible home ranges (rhr): a new, userfriendly R package for analyses of wildlife telemetry data. Wildl. Soc. Bull. 39, 358-363. doi: 10.1002/wsb.539 
Sims, D. W. (2005). "Differences in habitat selection and reproductive strategies of male and female sharks," in Sexual Segregation in Vertebrates: Ecology of the Two Sexes, eds K. E. Ruckstuhl and P. Neuhaus (New York: Cambridge University Press), 127-147.

Spaet, J. L. Y., Lam, C. H., Braun, C. D., and Berumen, M. L. (2017). Extensive use of mesopelagic waters by a Scalloped hammerhead shark (Sphyrna lewini) in the Red Sea. Anim. Biotel. 5, 1-12. doi: 10.1186/s40317-017-0135-x

Spencer, S. R., Cameron, G. N., and Swihart, R. K. (1990). Operationally defining home range: temporal dependence exhibited by hispid cotton rats. Ecology 71, 1817-1822. doi: 10.2307/1937590

Streich, M. K., Ajemian, M. J., Wetz, J. J., and Stunz, G. W. (2017). A comparison of fish community structure at mesophotic artificial reefs and natural banks in the western Gulf of Mexico. Mar. Coast. Fish. 9, 170-189. doi: 10.1080/19425120. 2017.1282897

Teo, S. L. H., Boustany, A., and Block, B. A. (2007). Oceanographic preferences of Atlantic bluefin tuna, Thunnus thynnus, on their Gulf of Mexico breeding grounds. Mar. Biol. 152, 1105-1119. doi: 10.1371/journal.pone.0116638

TinHan, T. C., Mohan, J. A., Dumesnil, M., DeAngelis, B. M., and Wells, R. J. D. (2018). Linking habitat use and trophic ecology of spotted seatrout (Cynoscion nebulosus) on a restored oyster reef in a subtropical estuary. Estuaries Coast. 41, 1793-1805. doi: 10.1007/s12237-0180391

Wood, S. N. (2006). Generalized Additive Models: An Introduction with R. Boca Raton, FL: CRC Press.

Conflict of Interest Statement: The authors declare that the research was conducted in the absence of any commercial or financial relationships that could be construed as a potential conflict of interest.

The reviewer YP and handling editor declared their shared affiliation at the time of the review.

Copyright (c) 2018 Wells, TinHan, Dance, Drymon, Falterman, Ajemian, Stunz, Mohan, Hoffmayer, Driggers and McKinney. This is an open-access article distributed under the terms of the Creative Commons Attribution License (CC BY). The use, distribution or reproduction in other forums is permitted, provided the original author(s) and the copyright owner(s) are credited and that the original publication in this journal is cited, in accordance with accepted academic practice. No use, distribution or reproduction is permitted which does not comply with these terms. 